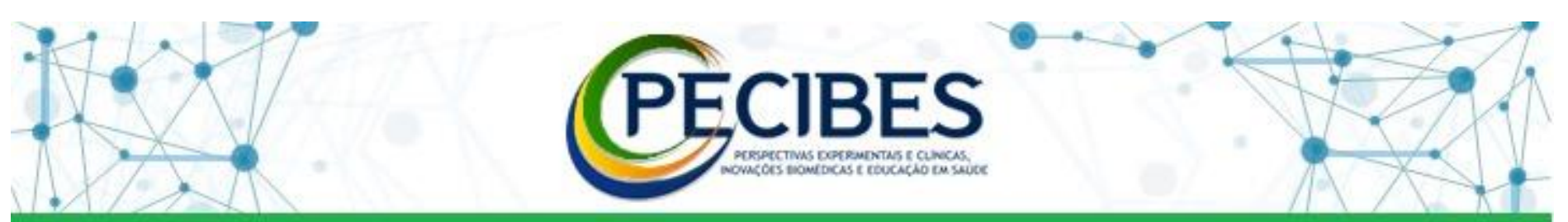

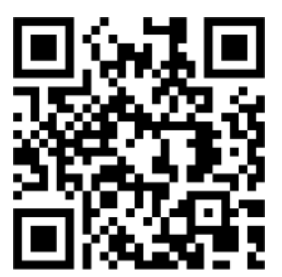

http://www.seer.ufms.br/inde x.php/pecibes/index

*Autor correspondente: Amanda de Oliveira Arguelho, Universidade Federal de Mato Grosso do

Sul -UFMS.

E-mail do autor: amanda.arguelho@ufm s.br

Descritores: Crianças. Covid-19. Isolamento Social.

Desenvolvimento

Infantil.

$\begin{array}{lr}\text { Key-words: } & \text { Kids. } \\ \text { Covid-19. } & \text { Social } \\ \text { isolation. } & \text { Child }\end{array}$
development. Palabras clave: Niños. COVID19. Aislamiento social. Desarrollo infantil.

\section{Influência e percepção dos pais no brincar de seus filhos durante a pandemia do covid-19}

\author{
Parent's Influence and Perception on Playing in Children During The Covid-19 Pandemic
}

Amanda de Oliveira Arguelho1, Daniele de Almeida Soares Marangoni², Andréa Baraldi Cunha $^{3}$, Rosana Machado de Souza Soares ${ }^{4}$.

1 Fisioterapeuta, Mestranda no Programa de Pós Graduação em Ciências do Movimento, Universidade Federal de Mato Grosso do Sul, Campo Grande, Mato Grosso do Sul, Brasil.

2 Fisioterapeuta, Docente do Programa de Pós Graduação em Ciências do Movimento, Universidade Federal de Mato Grosso do Sul, Campo Grande, Mato Grosso do Sul, Brasil

3 Fisioterapeuta, Docente na Universidade de Delaware, Newark, Estados Unidos.

4 Fisioterapeuta, Docente na Universidade Federal de Sergipe, Lagarto, Sergipe, Brasil.

Introdução: Durante a pandemia do COVID-19 diversas familias enfrentaram o desafio de ter as crianças em casa em tempo integral. Não foram encontrados na literatura estudos quanto às facilidades e dificuldades dos pais em lidar com todos os aspectos relacionados ao cuidado e necessidade do brincar da criança neste período. Objetivo: Verificar a influência e percepção dos pais sobre o brincar com seus filhos durante o distanciamento social no Brasil. Material e métodos: Estudo tipo survey, aprovado pelo Comitê de Ética em Pesquisa em Seres Humanos (CEP/UFMS) pelo parecer 4.473.475, em 18 de dezembro de 2020. Foi aplicado um questionário on-line e anônimo pelo WhatsApp, Instagram e Facebook, com pais de crianças com idade de 0 a $<4$ anos residentes no Brasil. As perguntas abordavam os seguintes aspectos: as características da criança e da família; a percepção dos pais sobre sua capacidade parental e limitações do brincar; e a percepção dos pais sobre as escolhas de estímulos que oferecem ao filho no cotidiano. O questionário foi construído por 3 especialistas em desenvolvimento infantil e avaliado por 4 mães antes do início da coleta de dados. Foi realizada análise descritiva, utilizando-se valores médios e proporções. Resultados: A idade média dos pais foi de $35,0 \pm 4,8$ anos, e das crianças de 22,5 511,3 meses. Os pais relataram que a frequência de brincadeiras com os filhos era maior $(59,6 \%)$ ou igual $(36,2 \%)$ em relação a antes do período de distanciamento social; $63,1 \%$ deixavam seus filhos brincar livremente enquanto realizavam outras atividades rotineiras. A maioria das crianças $(66,7 \%)$ passava mais tempo brincando com um aparelho com tela do que antes do distanciamento social. Conclusão: Mesmo com aumento da interação entre pais e filhos, o tempo das crianças nas telas também aumentou, fator preocupante no processo de desenvolvimento global que deve ser investigado. 